\title{
Risk Analysis and Control Measures for Slurry Shield Tunneling Diagonally under an Urban River Embankment
}

\author{
Yu Liang $\mathbb{D},{ }^{1}$ Xiangyu Chen $\mathbb{D}^{2},{ }^{2}$ Junsheng Yang, ${ }^{3}$ and Linchong Huang $\mathbb{D}^{1}$ \\ ${ }^{1}$ School of Aeronautics and Astronautics, Sun Yat-Sen University, Shenzhen, Guangdong 518000, China \\ ${ }^{2}$ Foshan Rail Transit Design and Research Institute Co. Ltd., Foshan, Guangdong 528000, China \\ ${ }^{3}$ School of Civil Engineering, Central South University, Changsha, Hunan 410000, China \\ Correspondence should be addressed to Linchong Huang; hlinch@mail.sysu.edu.cn
}

Received 24 May 2020; Revised 26 October 2020; Accepted 3 November 2020; Published 17 November 2020

Academic Editor: Valeria Vignali

Copyright () $2020 \mathrm{Yu}$ Liang et al. This is an open access article distributed under the Creative Commons Attribution License, which permits unrestricted use, distribution, and reproduction in any medium, provided the original work is properly cited.

\begin{abstract}
The construction of urban cross-river tunnels usually requires passing under river embankments, which inevitably disturbs the embankment substratum and causes ground deformation. Previous engineering cases have shown that embankment settlement is greater than ordinary surface settlement and that uneven settlement results in cracks of in the embankment, reducing the embankment stability. Based on a cross-river tunnel project in China, the construction risks caused by the additional stress on the embankment substratum, asymmetrical embankment load, and shield tunneling in saturated fine sand are analyzed during a large-diameter slurry shield tunneling below an urban river embankment diagonally. Additionally, relevant risk control measures, such as slurry pressure, jacking thrust setting, and driving velocity in the saturated fine sand stratum, are evaluated. The results show that during shield tunneling under a diagonal urban river embankment, the additional stress and asymmetrical load effects should be considered, and the shield slurry pressure and jacking thrust should be adjusted according to the distance between the cutter head and the embankment. Furthermore, based on settlement monitoring data, the driving velocity of the shield should be reasonably adjusted in a timely manner to avoid disturbing the fine sand stratum below the embankment.
\end{abstract}

\section{Introduction}

With rapid urban development, methods for quickly crossing a river and linking the two sides of a city have become the main concerns for modern society, and the utilization of cross-river shield tunnels has become an inevitable choice for its excellent tunneling speed, lower environmental impact, and good seismic performance. The Channel Tunnel (1994), the Tokyo Bay cross-sea tunnel (1997, Japan), the Elbe River fourth highway tunnel (2003, Germany), the "Green Heart" railway tunnel (2007, Netherlands), the Port Miami road tunnel (2003, USA), the Orlovsky River road tunnel (under construction, Russia), and the new Suez Canal tunnel (under construction, Egypt) are examples of famous cross-river shield projects with large diameters around the world. In recent years, with the increasing maturity of shield tunneling technology and the continuous increase in the economic level, China has begun a large-scale wave of shield tunneling construction under rivers or seas [1]. Statistics on the cross-river shield tunnels with diameters of more than $10 \mathrm{~m}$ in China that have been built or are under construction are shown in Figure 1 (up to July 2019). The figure clearly shows that the construction of shield tunnels across rivers or seas in China has increased dramatically. At present, at least 48 large-diameter shield tunnels (with diameters greater than $10 \mathrm{~m}$ ) have been built (27) or are under construction (21), among which more than 30 large-diameter shield tunnels have diameters greater than $14 \mathrm{~m}$.

During the construction of a cross-river shield tunnel, the soil above the tunnel in the flood plain near the river usually features a shallow water table in sandy strata $[2,3]$. Compared with clayey strata, the mechanical properties of sandy strata are more complex and less stable [4]. Instability is easily generated during surface excavation, and even surface collapses may occur [5]. 


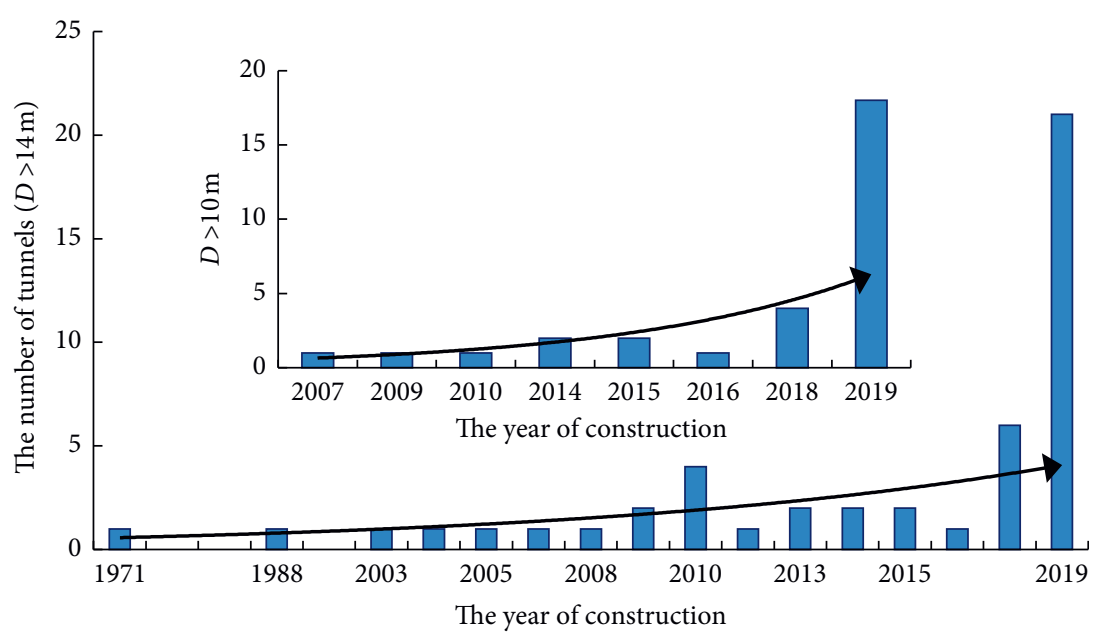

Figure 1: Construction of large-diameter cross-river/sea shield tunnels in China.

River embankments are usually adjacent to the main city road and represent an important barrier in the flood control system of the city. The safety of people's lives, property, and buildings nearby will be seriously threatened if the embankment is damaged. Engineering cases have shown that the settlement of the river embankment where the shield tunnels through can be much greater than that of the ground surface, and uneven settlement likely leads to embankment cracking, threatening the stability and safety of the embankment. Reasonable and effective measures should be taken when shield tunneling passes under an embankment to ensure the safety of the structure and of the shield tunneling project.

Lin et al. [6] summarized the primary factors influencing embankment settlement and proposed that shield excavation parameters have significant influences on tunnelinginduced embankment settlement. Furthermore, slight heaves caused by excess face-support pressure can compensate for ground loss. Shield tunneling with a high degree of guidance control can reduce disturbance in the surrounding soils.

Ren et al. [7] established a three-dimensional nonlinear finite element model to analyze the characteristics of the settlement and deformation of the Qiantang River embankment when a small-diameter shield tunnel crossed under the embankment and paid special attention to the large impact of the prerelease of methane from the stratum on the surface settlement of the embankment. Zhang et al. [8] and Jiang and Yu [9] analyzed the settlement of the Qiantang River embankment caused by another slurry balance shield (with a diameter of $11.68 \mathrm{~m}$ ) that passed under the embankment. Based on field measurements, the maximum settlement at the top of the embankment reached $30.5 \mathrm{~mm}$, and the transverse settlement curve matched a Gaussian normal distribution. The tunneling-induced disturbance to surrounding soil, the complex structure of the embankment, and the rainfall were considered the reasons that the settlement of the embankment was larger than that of other sections. Moreover, measures to reduce or avoid the safety risks when shield tunneling passes under an embankment were proposed.
Yao et al. [10] summarized the measures for effectively controlling the settlement when a subway shield tunnel crossed the Yangtze River embankment, such as segment assembly control, shield attitude control, and automatic settlement monitoring. Based on the Nanjing Weisan road crossriver tunnel passing under the Yangtze River embankment, Zhang et al. [11] found that the maximum tunneling-induced surface settlement occurred in the central portion of the top of the embankment. The grouting effect, slope of the embankment, and tunnel depth had a great influence on the embankment settlement. Before shield tunneling through the embankment, Ji and Wang [12] put forward a prereinforcement method involving a vacuum-based process combined with surcharge preloading of the embankment. Hence, the consolidation deformation and settlement caused by shield tunneling through the reinforced embankment were limited.

The studies above mainly focused on optimizing the shield tunneling parameters to reduce the construction risk when passing under a river embankment. However, little attention has been paid to the influence of the embankment's own factors, such as the stratum lying under the embankment, the angle of the shield tunneling crossing the embankment, and the additional stress effect of the embankment. This paper analyzed the construction risk caused by a large-diameter slurry shield (with a diameter of $11.3 \mathrm{~m}$ ) passing under a river embankment at an angle while considering the embankment factors mentioned above, and an adjustment scheme is put forward for use during tunneling under a river embankment in a saturated fine sand stratum.

\section{Project Overview}

The geographical location of the large-diameter shield tunnel is shown in Figure 2, and as shown, the project includes two separate tunnels. The northern tunnel is $1615 \mathrm{~m}$ long, and the southern tunnel is $1423 \mathrm{~m}$ long. A shield launching well is set on the east bank of the river, and the main entrance of the northern tunnel and three exit ramps of the southern tunnel are also located on the east bank and are connected to two main urban roads. Two shield receiving 


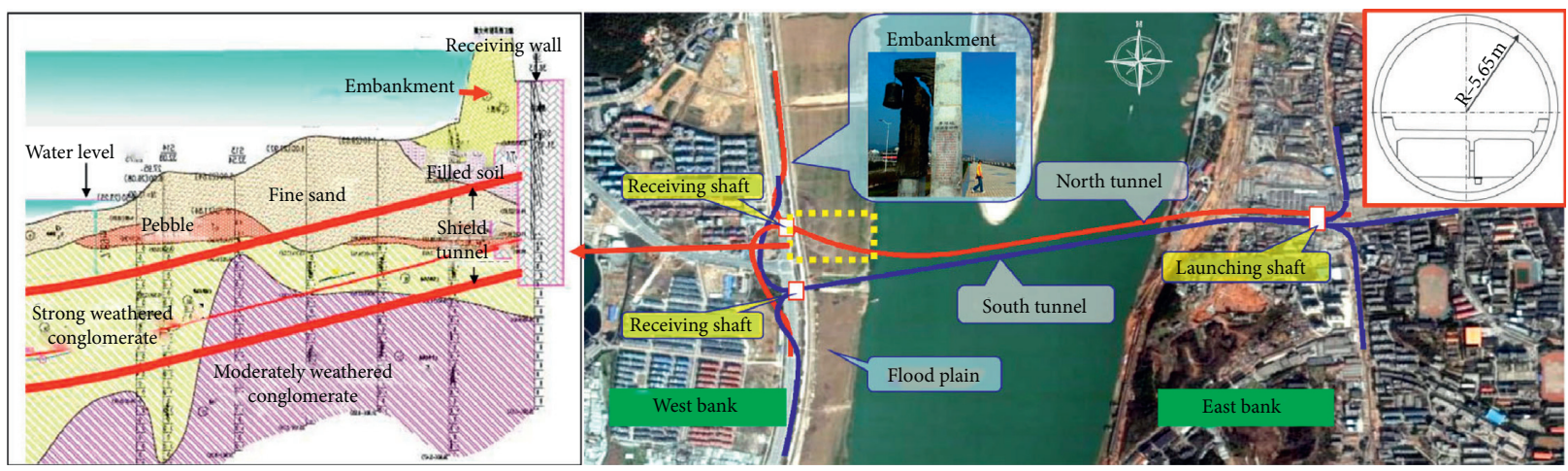

Figure 2: Overview of the cross-river shield tunnel.

wells are set for the southern and northern tunnels on the west bank of the river, and four ramps are connected with the main urban roads in a butterfly mode, as shown in Figure 2. The excavation diameter of the shield is $11.65 \mathrm{~m}$. The single-lining-type tunnel segment is adopted, with an $11.3 \mathrm{~m}$ outer diameter, $10.3 \mathrm{~m}$ inner diameter, $50 \mathrm{~cm}$ thickness, and $2.0 \mathrm{~m}$ ring width per segment. Each segment ring is circumferentially partitioned into 9 blocks (that is, 6 standard blocks, 2 adjacent blocks, and 1 sealing block). The shield tunnels from east to west across the river and passes under the embankment of the west bank at an angle of $57^{\circ}$ and a burial depth of $14.5 \sim 16.1 \mathrm{~m}$.

The embankment that the shield passes under was built in 2000 and collapsed once during flooding, resulting in heavy losses. The embankment is mainly filled with compacted soil with a low structural stiffness and poor integrity. During construction of the shield receiving well on the west side of the embankment, a part of the well was broken and reinforced by grouting. The strata underlying the embankment are as follows (from top to bottom): miscellaneous filled soil, fine sand, pebbles, strongly weathered conglomerate, and moderately weathered conglomerate, and the shield tunneling mainly passes through the miscellaneous filled soil, fine sand (which is saturated with water and has a low to moderate density), and strongly weathered conglomerate, as shown in Figure 2.

\section{Risk Analysis of Shield Tunneling under the Embankment}

The ground loss and the disturbance to surrounding strata caused by shield tunneling can both contribute to embankment settlement, with the latter being the main contributor to embankment settlement [13]. According to similar engineering cases, shield tunneling-induced surface settlement in areas other than the embankment tended to be limited after the shield passed through, whereas the surface settlement of the embankment was much larger. Based on a typical crossriver shield tunnel project, the construction risk caused by the effects of additional stress, asymmetrical load of the embankment, and the strata underlying the embankment during the process of a large-diameter slurry shield tunneling diagonally under the river embankment are analyzed.
3.1. The Effect of the Additional Stress Imposed by the Embankment on the Shield Slurry Pressure. The shield slurry pressure usually changes with the depth of overlying soil [14]. If the slurry pressure is not controlled properly to balance the pressure of the soil and water on the excavation face, the excavation face will be unstable, and excessive displacement of the surrounding stratum will occur, thereby endangering the overlying embankment structure. As the shield cutter head approaches the embankment, the additional stress on the underlying stratum caused by the embankment's load must be taken into account when setting the slurry pressure of the shield [15].

The embankment is mainly filled with compacted soil, and the bulk density of the embankment is $22 \mathrm{kN} / \mathrm{m}^{3}$. The western part of the embankment was partially dismantled by the construction of the shield receiving well and reinforced by grouting, so the load of the embankment can be simplified as a semitrapezoidal load (Figure 3). In the actual calculation, it was assumed that the buried depth of the tunnel within a given distance as the shield passed under the embankment remained unchanged, that is, the influences of changes in ground elevation and the longitudinal slope of the tunnel were excluded (the actual longitudinal slope is $5.2 \%)$. Taking the embankment load as a plane strain problem, the corresponding additional stress of the foundation was calculated by means of integration with the Businesk solution [16]. Under the action of the semitrapezoidal distributed load $\mathrm{ABCD}$, the calculation results of vertical additional stress $\sigma_{z}$ at the buried depth of the tunnel axis $(z=16.1 \mathrm{~m})$ is shown in Figure 3 ( $x$ represents the distance between the shield cutter head and the embankment foot and is positive in the driving direction).

Table 1 shows the soil parameters needed to calculate the additional stress, where $h_{i}$ is the thickness of each stratum; $\gamma$ is the bulk density of the embankment soil; $K_{0}$ and $K_{a}$ are the coefficients of static lateral soil pressure and active lateral soil pressure, respectively; and $c$ and $\varphi$ are the cohesion and internal friction angle of the soil, respectively.

For slurry shields, the slurry pressure is usually the sum of pore water pressure, horizontal soil pressure on the excavation face, and preloading (usually $20 \sim 30 \mathrm{kN} / \mathrm{m}^{2}$ ), considering setting error and fluctuation in the slurry pressure. According to construction experience and Rankine soil 


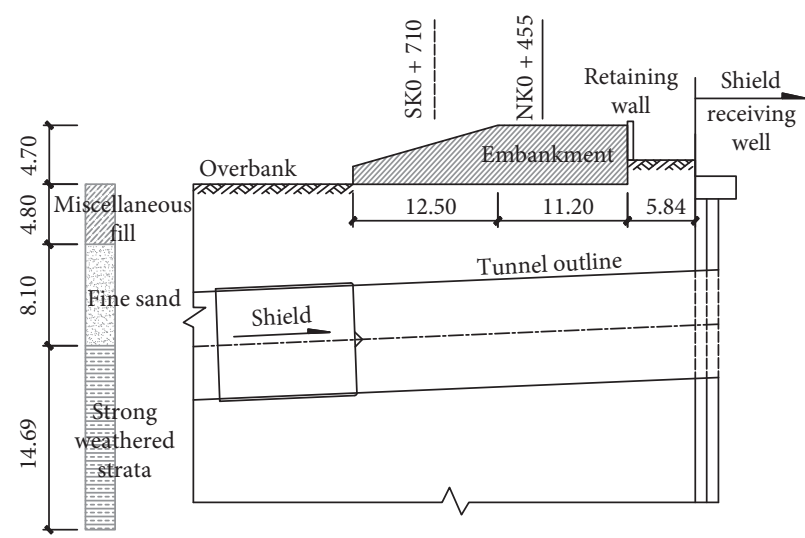

(a)

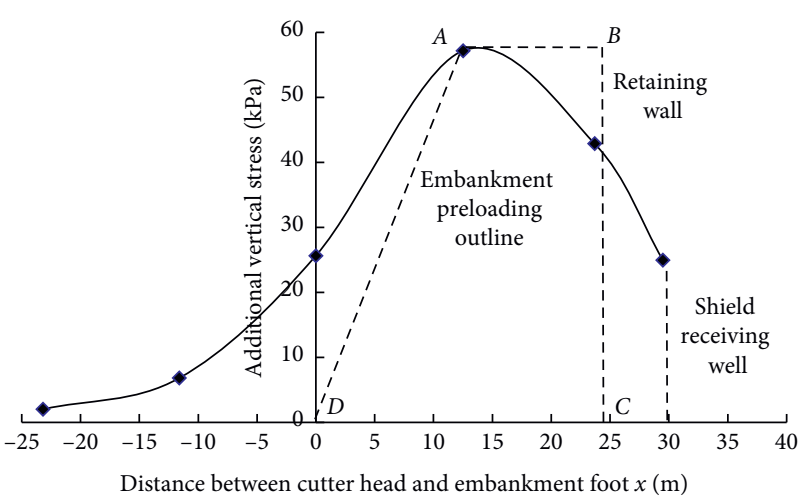

(b)

FIGURE 3: Sketch and the simplified load distribution of the river embankment (unit: m).

TABLE 1: Soil parameters.

\begin{tabular}{lcccccc}
\hline Soil parameters & $\begin{array}{c}h_{i} \\
\mathrm{~m}\end{array}$ & $\begin{array}{c}\gamma \\
\mathrm{kN} / \mathrm{m}^{3}\end{array}$ & $\begin{array}{c}K_{0} \\
-\end{array}$ & $\begin{array}{c}K_{a} \\
-\end{array}$ & $\begin{array}{c}c \\
\mathrm{kPa}\end{array}$ & $\begin{array}{c}\varphi \\
{ }^{\circ}\end{array}$ \\
\hline Filled soil & 4.8 & 19.5 & 0.54 & 0.76 & 12 & 8 \\
Fine sand & 8.1 & 19.0 & 0.43 & 0.36 & 5 & 30 \\
\hline
\end{tabular}

pressure theory, the upper and lower limits of slurry pressure were calculated as follows [17-19]:

$$
\begin{aligned}
P_{\mathrm{fu}}= & P 1+P 2+P 3+P 4 \\
= & \gamma_{w} h+K_{0}\left[\left(\gamma-\gamma_{w}\right) h+\gamma(H-h)\right]+20+K_{0} \sigma_{z}, \\
P_{\mathrm{fl}}= & P 1+P 2+P 3 \\
= & \gamma_{w} h+K_{a}\left[\left(\gamma-\gamma_{w}\right) h+\gamma(H-h)\right] \\
& -2 c \sqrt{K_{a}}+20+K_{a} \sigma_{z}
\end{aligned}
$$

where $P_{\mathrm{fu}}$ is the upper limit value of slurry pressure $(\mathrm{kPa}) ; P_{\mathrm{fl}}$ is the lower limit value of slurry pressure $(\mathrm{kPa})$; and $P_{1}, P_{2}$, and $P_{3}$ are the groundwater pressure, formation of lateral earth pressure, and preset slurry pressure, respectively, and in this project, $P_{3}=20 \mathrm{kPa}$. Additionally, $h$ and $H$ are the depth from the underground water level to the tunnel axis and from the ground level to the tunnel axis (m), respectively. In this project, $h=H . \gamma_{w}$ is the bulk density of water $\left(\mathrm{kN} / \mathrm{m}^{3}\right), P_{4}$ is the lateral force generated by the embankment during shield tunneling. If the effect of the additional stress on the underlying strata generated by the embankment is not taken into account (i.e., only the self-weight of the embankment is taken into account), $P_{4}=\gamma_{R} h_{e}(x)$, where $\gamma_{R}$ is the bulk density of the embankment, and $h_{e}(x)$ is the height of the embankment at coordinate $x$. If the additional stress is considered, $P_{4}=K \sigma_{z}$, where $K=K_{0}$ when calculating $P_{\mathrm{fu}}$ and $K=K_{a}$ when calculating $P_{\mathrm{fl}}$. All other parameters are the same as above.

During shield tunneling, the actual slurry pressure should be set within the range of theoretical upper and lower limits. According to the formula mentioned above, the

\begin{tabular}{|c|c|c|c|c|c|}
\hline \multirow{2}{*}{$\begin{array}{l}\text { Distance } \\
x(\mathrm{~m})\end{array}$} & \multirow{2}{*}{$\begin{array}{c}\text { Additional stress } \\
\sigma_{z}\end{array}$} & \multicolumn{2}{|c|}{$\begin{array}{c}\text { Not } \\
\text { considering } \\
\sigma_{z}\end{array}$} & \multicolumn{2}{|c|}{$\begin{array}{l}\text { Considering } \\
\qquad \sigma_{z}\end{array}$} \\
\hline & & $P_{\mathrm{fu}}^{\prime}$ & $P_{\mathrm{fl}}^{\prime}$ & $P_{\mathrm{fu}}$ & $P_{\mathrm{fl}}$ \\
\hline-23.2 & 2.0 & 201.6 & 179.7 & 202.4 & 180.4 \\
\hline-11.6 & 6.8 & 201.6 & 179.7 & 204.5 & 182.2 \\
\hline 0.0 & 25.6 & 201.6 & 179.7 & 212.6 & 189.0 \\
\hline 12.5 & 57.2 & 246.0 & 216.9 & 226.2 & 200.3 \\
\hline 23.7 & 42.9 & 246.0 & 216.9 & 220.0 & 195.2 \\
\hline 29.5 & 25.0 & 201.6 & 179.7 & 212.3 & 188.7 \\
\hline
\end{tabular}
calculated upper and lower limits of slurry pressure are shown in Table 2 with and without consideration of the effect of the additional stress.
TABle 2: Computation of slurry pressure (unit: $\mathrm{kPa}$ ).

As shown in Table 2, the additional stress was less than $2.0 \mathrm{kPa}$ when the shield was at a distance of greater than two times the shield diameter $(x<-24 \mathrm{~m})$ from the foot of the embankment, which had little influence on the setting of slurry pressure. Within a range of one shield diameter from the foot of the embankment $(-12 \mathrm{~m} \leq x \leq 0)$, the additional stress showed a significant increasing trend, and the maximum value below the embankment was $57.2 \mathrm{kPa}$ $(x=12.5 \mathrm{~m})$. With increasing distance, the additional stress decreased. The upper limit and lower limit curves of slurry pressure corresponding to the two algorithms are shown in Figure 4 .

As shown in Figure 4, the effect of additional stress on the underlying strata generated by the embankment had a significant impact on the set slurry pressure:

(1) When the cutter head of the shield was approximately one shield diameter away from the embankment foot, the set slurry pressure began to rise gradually under the influence of the additional stress; when the cutter head of the shield passed under the embankment from the embankment foot to the top of the embankment platform, the slurry pressure continued to rise to the maximum value. The slurry pressure then decreased gradually as the cutter head of the shield passed under the remainder of the embankment. 


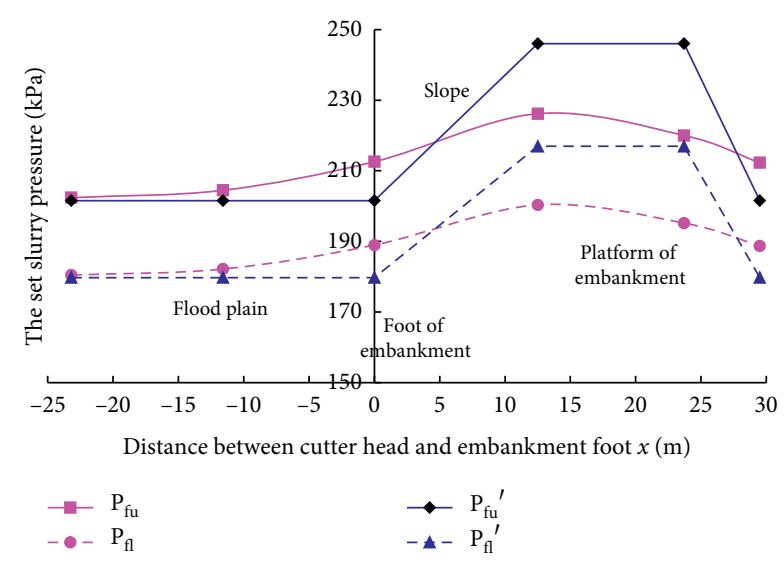

FIgURE 4: Upper and lower limit value curves of slurry pressure.

(2) If the effect of additional stress is not taken into account, the set slurry pressure started to rise when the cutter head reached the embankment foot, and the slurry pressure remained at the maximum value as the shield passed under the embankment platform. This pattern led to a small set slurry pressure value (maximum difference of $11 \mathrm{kPa}$ at $x=0 \mathrm{~m})$ at the foot of the embankment and a large set slurry pressure value (maximum difference of $26 \mathrm{kPa}$ at $x=23.7 \mathrm{~m}$ ) at the platform of the embankment.

Two disadvantages appear to be associated with the situation in which the additional stress effect on the underlying strata caused by the embankment load is not considered:

(1) A slurry pressure that is too low when the slurry shield is close to or under the foot of the embankment could lead to instability in the excavation face, causing excessive settlement and even surface cracking of the embankment

(2) A slurry pressure that is too high when the slurry shield is below the center of the embankment could cause excessive disturbance to the excavation face and surrounding soil and even cause surface uplift of the embankment, thereby threatening the stability and safety of the embankment

\subsection{The Effect of the Asymmetrical Load of the Embankment} on Shield Jacking Thrust. The shield passed under the embankment at an angle, which increases the tunneling range through the embankment and thus increases the influence of the load of the embankment on the control of the shield. In this example, the shield tunnel crossed diagonally at an angle of $57^{\circ}$ under the embankment. The load of the embankment varied asymmetrically across the tunnel section, and an asymmetrical load existed on both sides of the tunnel shield axis, as shown in Figure 5.

$A, B$, and $C$ are the three isometric distribution points on the horizontal centerline of the shield cutter head, $\mathrm{AB}=\mathrm{BC}=2 / \mathrm{D}$. Point $A$ was the first point on the shield cutter head to approach the embankment foot, and point $C$ was the last one. Considering the additional stress effect, the upper and lower limit values of support pressure at $A$ and $C$ can be calculated when the shield passes through regions 1 and 2 (the shaded parts), as shown in Figure 6.

According to Figure 6, when the cutter head of the shield passed through the $\mathrm{M}-\mathrm{T}$ section, the support pressure set at point $A$ rose continuously. Due to the influence of additional stress caused by the load of the embankment, the support pressure set at point $C$ increased markedly when the shield passed through the Q-R section and then decreased gradually beyond the $R$ section. In the process of passing through the $\mathrm{M}-\mathrm{Q}$ section, the average support pressure $\left(\left(P_{\mathrm{fu}}+P_{\mathrm{fl}}\right) / 2\right)$ set at point $A$ was greater than that at point $C$, and the max difference in section $Q$ was $21 \mathrm{kPa}$. As the shield cutter head passed through the Q-R section, the average support pressure set at point $C$ increased eventually and exceeded the support pressure at point $A$, and the max difference at the $R$ section was $10 \mathrm{kPa}$. As the shield cutter head passed through the R-T section, the average support pressure set at point $C$ decreased, gradually dropping below that at point $A$, and the max difference in section $T$ reached $23 \mathrm{kPa}$.

In conclusion, when large-diameter shield tunneling occurs diagonally through an embankment, the required support pressure on the two sides of the cutter head of the shield did not change in a symmetrical manner because of the effect of the asymmetrical load of the embankment. If the influence of the asymmetrical load were not considered, the following risks would exist:

(1) When the shield cutter head passed under the foot and slope of the embankment (M-Q section, calculating area 1) diagonally, a small shield jacking thrust on the side of point $A$ would cause soil instability in the excavation face, leading to uneven settlement of the embankment, and excessive settlement would probably induce cracking in the embankment surface.

(2) When the shield cutter head passed under the slope and platform of the embankment ( $\mathrm{R}$ section, calculation area 2) diagonally, a small shield jacking thrust on the side of point $C$ would cause uneven settlement of the embankment. When passing under sections $S$ and $T$, if the jacking thrust set at the $C$ side of the excavation face was too large, the embankment surface would rise and affect the safety of the embankment. Therefore, when the shield passes under the embankment diagonally, the effect of the asymmetrical load of the embankment should be fully considered.

\subsection{The Effect of a Fine Sand Stratum Underlying the Em-} bankment on Tunneling. As shown in Figure 2, the strata at the excavation face of the shield and above are mainly saturated fine sand, which has complex mechanical characteristics, high permeability, and poor stability and is prone to large deformation due to external disturbance. It is difficult to tunnel in such stratum, and it is easy to cause 


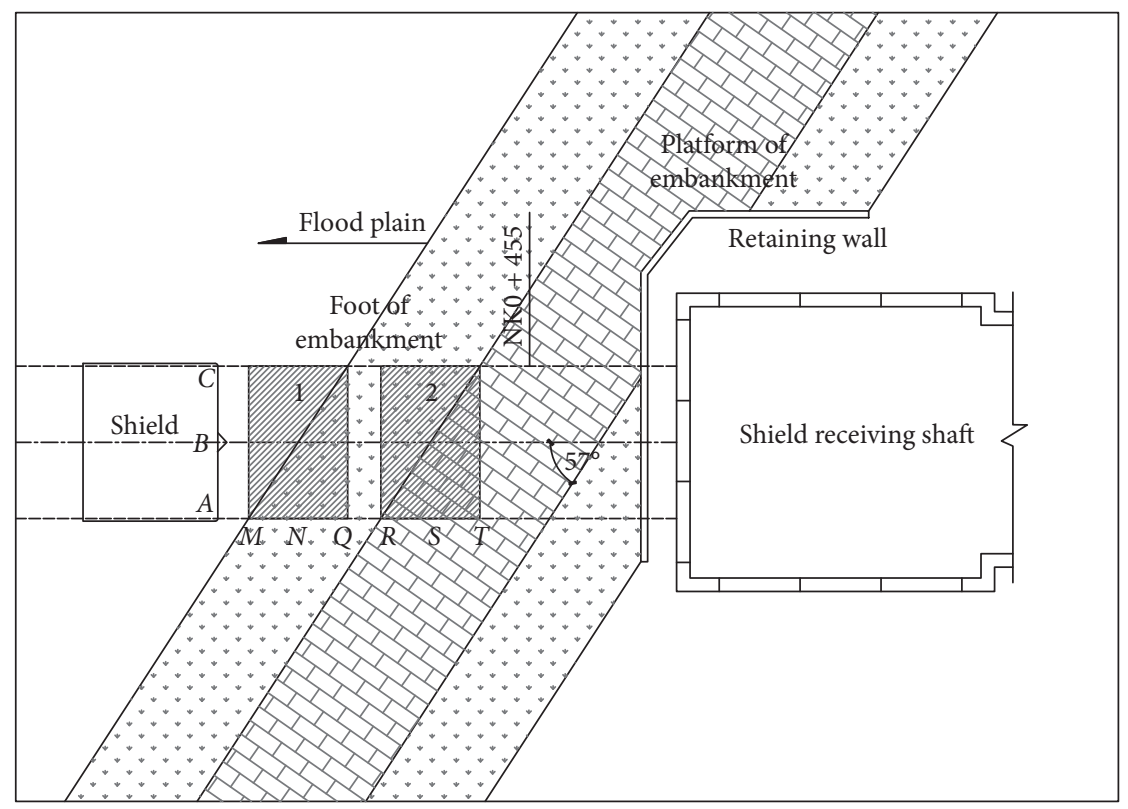

FIgURE 5: Sketch of the tunnel passing under the embankment.

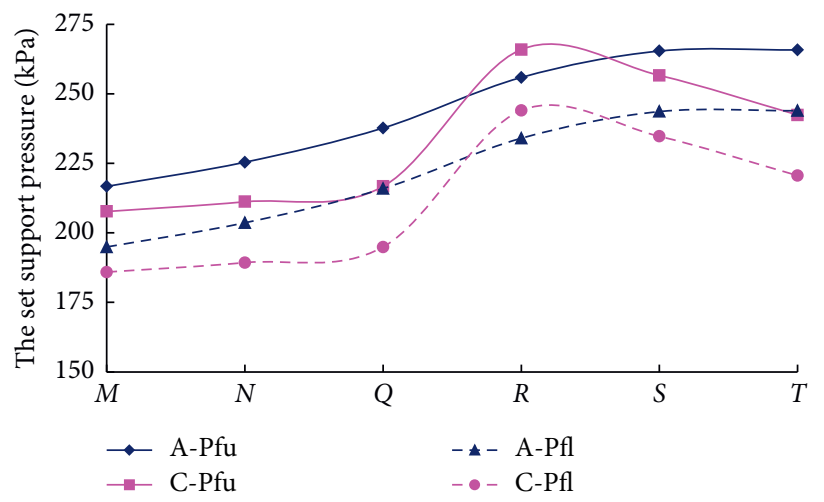

(a)

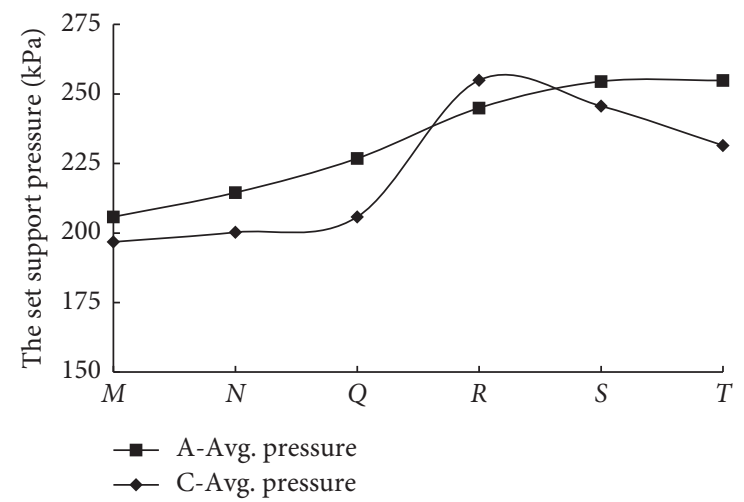

(b)

Figure 6: Slurry pressure curves for points $A$ and $C$ in regions 1 and 2.

instability in the excavation surface and even surface collapse during excavation.

As one of the most important tunneling parameters of shields, driving velocity has a significant impact on the embankment settlement caused by the disturbance of largediameter shields in saturated fine sand [3]. To reduce the settlement risk, a reinforcement of the soil is recommended [20]. High-pressure jet grouting reinforcement was carried out for the fine sand stratum in the significantly affected area before excavation of the southern line in the floodplain near the embankment [21]. The grouting reinforcement range in the fine sand stratum is shown in Figure 7. After grouting, the poor engineering characteristics of the fine sand should be improved, the pore ratio and permeability coefficient should be reduced, and the compactness and shear strength of the grout-mixed sandy soil should be greatly improved, especially for the cohesion of the soil [22]. After surface grouting reinforcement, the fine sand stratum was relatively homogeneous, and the shield tunneling parameters were stable and easy to control.

Figure 8 shows the variation curve of the shield driving velocity values for the northern and southern lines as the shield passed under the embankment. The average driving velocity of the northern line in this section was $\overline{v_{N}}=8.8 \mathrm{~mm} / \mathrm{min}$, with a standard deviation of $\sigma_{N}=4.0$. The average driving velocity of the southern line was $\overline{v_{S}}=3.4 \mathrm{~mm} / \mathrm{min}$, with a standard deviation of $\sigma_{S}=1.2$.

According to the statistics above, the driving velocity of the southern line was slow and remained relatively stable during tunneling under the embankment. When the northern line approached and passed the monitoring section, the driving velocity was markedly higher than that of the southern line, and the velocity fluctuated significantly.

Figure 9 shows the embankment settlement curve for the section $\mathrm{NK} 0+455$ on the northern line and section SK0 +710 (similar section as NK0+455) on the southern 


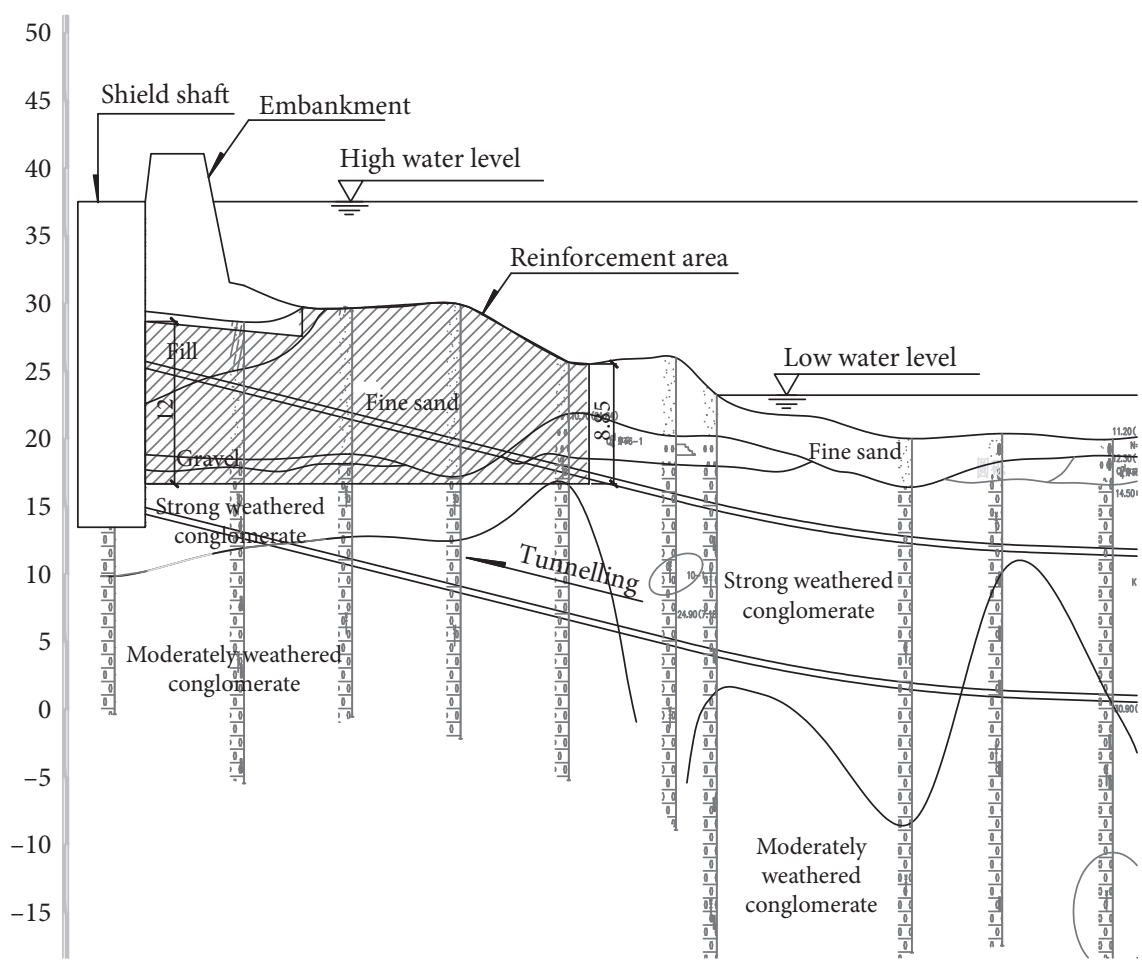

FIGURE 7: Longitudinal section of the grouting reinforcement area.

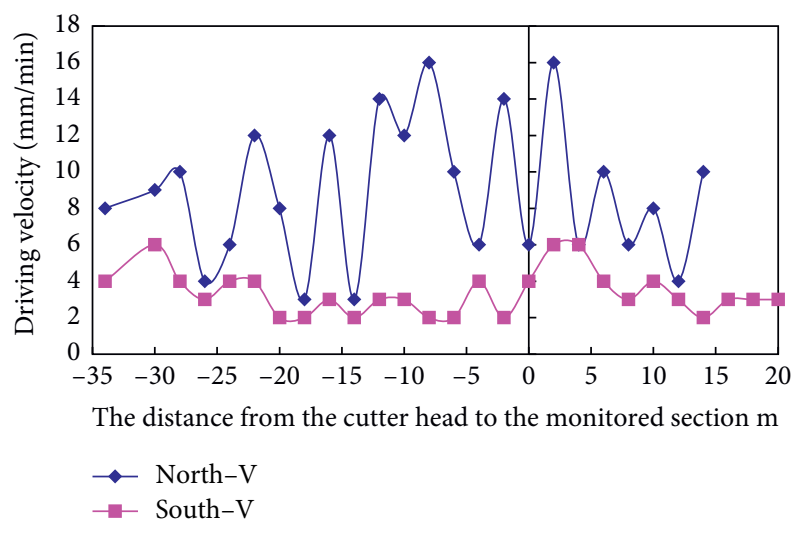

FIGURE 8: Curves of shield driving velocity as the shield passed under the embankment.

line. The settlement rate of the embankment was significantly higher than that of other sections when the shield passed under the embankment. The driving velocity of the shield in the northern line was faster than that in the southern line, and the surface settlement at the NK0 + 455 section on the northern line was significantly greater than that at the SK0 + 710 section on the southern line. In fact, as the northern line tunnel was excavated beneath the embankment, obvious cracks in the cross-sectional direction of the tunnel appeared on the platform of the embankment, as shown in Figure 9. After the crack occurred, the northern line shield stopped tunneling, and the mixed clay materials were used to backfill the crack. The frequency of monitoring and observation of crack development should be strengthened as a 24-hour tracking. The sleeve valve barrel grouting

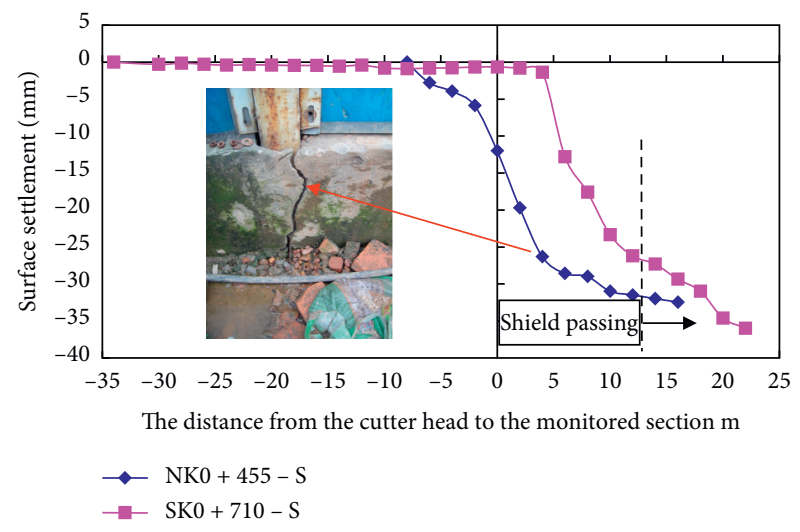

Figure 9: Settlement curves and cracks in the embankment.

reinforcement was carried out at the foot of the embankment, and the dynamic track grouting was continued until the settlement tended to be stable. Due to the grout reinforcement and other measures, no cracks occurred at the embankment when the southern line tunneled through.

From the analysis above, when the large-diameter slurry shield passed through the saturated fine sand stratum under the embankment, the shield driving velocity had a significant impact on the embankment settlement. If the driving velocity was fast and fluctuated greatly and synchronous application of reinforcement grouting was not carried out in a timely manner, and the stratum was greatly disturbed, which enhanced the uneven settlement of the fine sand stratum underlying the embankment, thus threatening its integrity. 


\section{Risk Control Measures When Shield Tunneling under the Embankment}

When the large-diameter slurry shield passed under the embankment diagonally, the effects of the additional stress on the underlying stratum, the asymmetrical load of the embankment, and the comprehensive properties of the fine sand stratum can all contribute to cracking of the embankment, thereby threatening the stability of the embankment and causing severe construction risks, if the shield tunneling parameters are not reasonably controlled. Therefore, it is necessary to adjust the construction parameters reasonably to ensure the safety of the embankment structure.

4.1. Slurry Pressure Control. As shown in Figure 10, the actual slurry pressure increased from $0.17 \mathrm{MPa}$ to $0.22 \mathrm{MPa}$ (an increase of 29.4\%) after the cutter head of the shield passed through the embankment foot, and the slurry pressure dropped to $0.18 \mathrm{MPa}$ (a decrease of $18.2 \%$ ) when the cutter head reached the bottom of the embankment platform. The actual slurry pressures in the foot and platform sections of the embankment were relatively small compared with the $P_{\mathrm{fu}}$ and $P_{\mathrm{fl}}$ when considering the additional stress generated by the embankment load. A low slurry pressure causes excavation face instability and affects the overall stability of the embankment. The monitoring results show that if the embankment experienced large uneven settlement, cracks could form.

The results also show that the additional stress generated by the embankment load should be taken into account when the shield passes under the embankment. When the cutter head of the shield is 1-2 shield diameters away from the foot of the embankment, the slurry pressure should be gradually increased to avoid soil instability on the excavation face. When the cutter head of the shield passes under the slope of the embankment, the slurry pressure should continue to increase and should reach a maximum value when the cutter head reaches the edge of the embankment platform (the increase should be approximately 10\%). As the cutter head of the shield passes under the rest of the embankment platform, the embankment load is diffused in the underlying stratum, the pressure transferred to the tunnel is greatly reduced, and the set value of slurry pressure should be gradually reduced.

4.2. Jacking Thrust Control. When the shield was under the platform of the embankment, cracks appeared on the platform oriented perpendicular to the direction of the tunnel. The widths and lengths of cracks on the right side of the tunnel axis (point A side) were slightly greater than that on the left side (point $\mathrm{C}$ side). The field monitoring data from the embankment (Figure 11) showed that the surface settlement of the embankment platform on the point $A$ side was much larger than that on the point $C$ side when the shield tunneled is under the embankment diagonally. According to the analysis above, due to the insufficient consideration of the influence of the asymmetrical load of the embankment during shield tunneling, the shield jacking thrust set on the

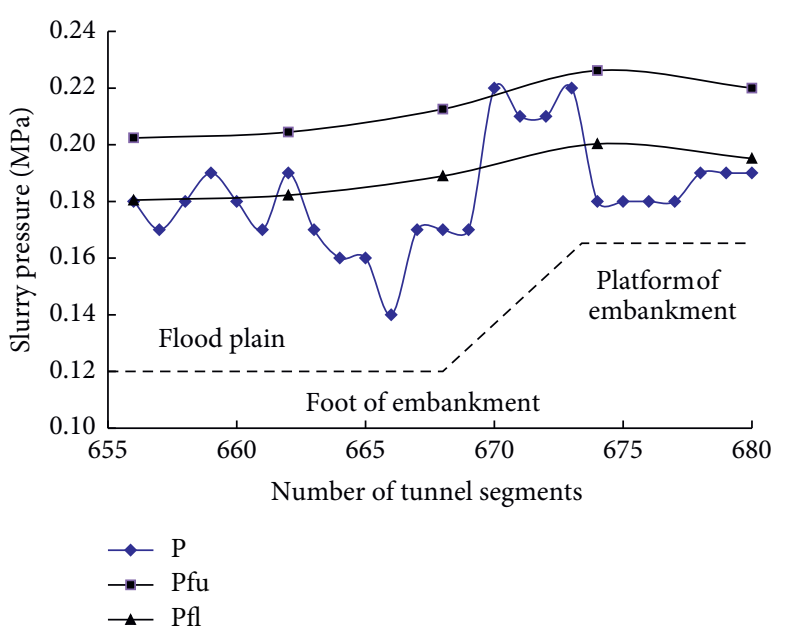

FIgURE 10: Curves of the actual slurry pressure during tunneling under the embankment.

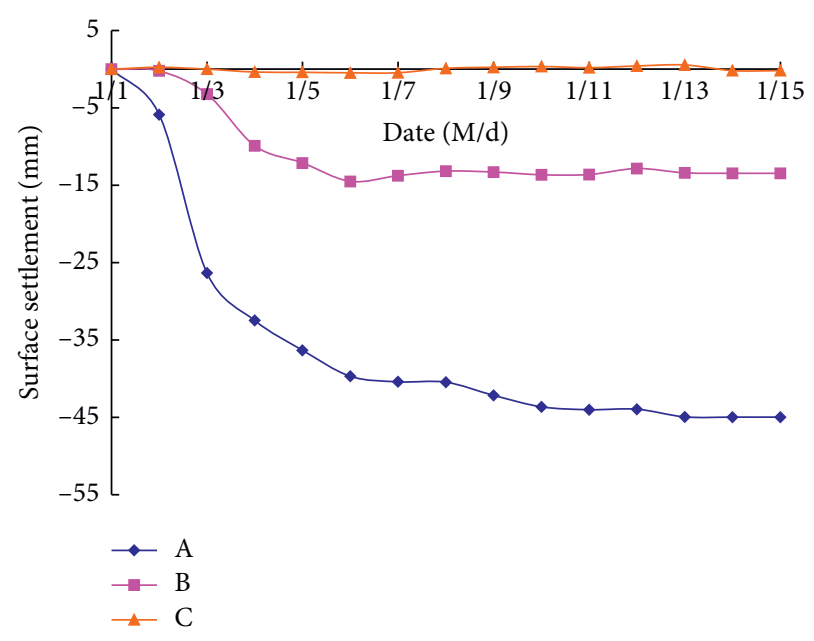

Figure 11: Settlement curves of the embankment platform $(\mathrm{NK} 0+455)$.

right side of the shield was too small, resulting in excess settlement on the right side of the tunnel axis (point A side), and the cracks that appeared on the right side of the axis were wider and longer.

The analysis above demonstrates that when a large-diameter slurry shield tunnels diagonally through an embankment, the thrust of jacks on both sides of the tunnel axis should be appropriately adjusted according to the actual asymmetrical situation:

(1) When the cutter head of the shield crosses through region 1 (foot to slope of the embankment), the thrust of the jacks should be appropriately increased on side $\mathrm{A}$ of the shield

(2) When the cutter head of the shield crosses through region 2 (slope to platform of the embankment), the thrust of the jacks should be significantly increased on side $\mathrm{C}$ of the shield first, gradually exceeding the thrust of the jacks on side A. When the cutter head of 
the shield was close to the $S$ section, the jacking thrust on side A should be increased, and the one on side $\mathrm{C}$ should be reduced to overcome the asymmetrical load of the embankment.

4.3. Driving Velocity Control. During tunneling through saturated fine sand stratum underlying an embankment, the shield driving velocity should be set to a reasonable constant value to effectively control the surface settlement of the embankment. When the shield tunneled beneath the river embankment for the northern line, the maximum driving velocity $v_{N}$ was $16 \mathrm{~mm} / \mathrm{min}$, and the average driving velocity $\overline{v_{N}}$ was $8.4 \mathrm{~mm} / \mathrm{min}$. The driving velocity was high and fluctuated greatly. The shield driving velocity was too high and failed to remain constant, which greatly disturbed the excavation face and the overlying fine sand stratum and aggravated the settlement of the embankment. When the shield tunneled beneath the river embankment for the southern line, the maximum driving velocity $v_{S}$ was controlled at $6 \mathrm{~mm} / \mathrm{min}$, and the driving velocity remained constant. Therefore, the excavation produced little disturbance in the fine sand of the excavation face, and the surface settlement of the embankment was significantly less than that of the northern line.

When large-diameter shield tunneling occurs in saturated fine sand strata underlying an embankment, the appropriate constant driving velocity should be set according to the monitoring data of the embankment settlement to avoid disturbing the stratum with a velocity that is too fast or unstable, which might enhance embankment settlement.

4.4. Other Risk Control Measures. When the slurry shield tunneled diagonally under a river embankment, the stratum under the embankment will suffer great disturbance, which is much larger than other sections. In addition to the above three important factors, other construction factors will also have an important impact on the overall stability of the embankment structure.

(1) Slurry circulation. Reasonable slurry circulation is necessary to ensure the balance of the shield excavation chamber. When a shield tunneled through the embankment, the flow rate of the incoming (short for $i$ ) and outgoing (short for $o$ ) slurries should be closely monitored to judge the change of excavated soil amount. In case of any abnormality, it should timely adjust the slurry flow rate so as to form a highquality slurry balance on the cutting surface and maintain the stability of the embankment structure. In this project, when the shield tunneled diagonally under the embankment, the average (i/o) slurry flow rate of northern line was $908 \mathrm{~m}^{3} / \mathrm{h}$ and $621 \mathrm{~m}^{3} / \mathrm{h}$ (severely slurry loss state) and that of southern line was $1008 \mathrm{~m}^{3} / \mathrm{h}$ and $1066 \mathrm{~m}^{3} / \mathrm{h}$ (slightly slurry loss state), respectively. It was indicated that the slurry circulation of southern line was more reasonable than that of northern line.
(2) Synchronous grouting. Before shield tunneling, the backfill grout should be prepared and suitable for the fine sandy stratum. When the shield tunneled through the embankment, synchronous grouting shall be carried out in time, and the amount of the grout shall be adjusted according to the settlement monitoring data of the embankment and the shield driving velocity. After the shield has tunneled through, secondary grouting should be carried out to inhibit the further ground deformation. When the shield tunneled diagonally under the embankment, the average grout pressure and grout amount of northern line was $0.21 \mathrm{MPa}$ and $21.37 \mathrm{~m}^{3} /$ ring and that of southern line was $0.22 \mathrm{MPa}$ and $22.22 \mathrm{~m}^{3} /$ ring, which was larger than the northern line.

(3) Long time shutdown. If the shield was shutdown under the embankment for a long time, the settlement of the embankment will increase, and it is difficult to control the jacking thrust and the attitude of the shield during reexcavation. Therefore, the shield equipment should be overhauled before the shield tunneling through the embankment to ensure the normal operation of the equipment.

(4) Rainfall. Crossing the embankment in rainy and flood season should be avoided. If it is continuously rainy when the shield is crossing the embankment, the slurry pressure should be appropriately increased by $0.01 \sim 0.02 \mathrm{MPa}$. Meanwhile, impervious treatment should be carried out in time to prevent the tensile cracks on the embankment roof and slope surface to further deepen the cracks.

\section{Conclusions}

Based on the case of a large-diameter slurry shield tunneling under a riverside embankment at an angle, this study analyzed the risk associated with the additional stress on the underlying stratum, the asymmetrical embankment load, and the comprehensive properties of the fine sand stratum, and the following conclusions were reached:

(1) When shield tunneling under an embankment, the effect of the additional stress on the underlying stratum should be considered. When the cutter head of the shield is 1-2 shield diameters away from the embankment foot, the slurry pressure should start to increase gradually; when the cutter head of the shield passes from the foot of the embankment to the slope of the embankment, the slurry pressure should continue to increase and reach a maximum value at the edge of the embankment platform (the magnitude of the increase should depend on the height and size of the embankment). When the cutter head of the shield passes under the rest of the embankment platform, the slurry pressure should be gradually decreased slightly.

(2) When a large-diameter slurry shield tunnels diagonally under an embankment, an asymmetrical load 
will exist on the excavation face, which has an obvious influence on the jacking force setting. When the cutter head of the shield passes from the foot of the embankment to the slope of the embankment, the jacking force close to the embankment side should be appropriately increased. When the cutter head of the shield passes through the section from the slope of the embankment to the bottom of the platform, the jacking force far from the embankment side should be greatly increased at first and then reduced, while the jacking force close to the side of the embankment should be increased to overcome the asymmetrical load effect.

(3) To reduce the settlement risk, a reinforcement of the soil is recommended when a large-diameter slurry shield tunnels through a saturated fine sand stratum underlying an embankment. The driving velocity has a significant impact on the embankment settlement, which should be adjusted in a timely and reasonable manner based on embankment settlement monitoring data to keep the velocity constant to avoid stratum and embankment disturbances caused by velocities that are too fast and too variable.

(4) In addition to the above three important factors, other construction factors will also have an important impact on the overall stability of the embankment structure, such as synchronous grouting, slurry circulation, shield maintenance, and long-term rainfall. The above factors are not further analyzed in this paper. A set of reasonable construction parameters and control measures should be put forward to ensure the safety of shield construction and the stability of embankment structure.

\section{Data Availability}

The data used to support the findings of this study are available from the corresponding author upon request.

\section{Conflicts of Interest}

The authors declare that they have no conflicts of interest.

\section{Acknowledgments}

This work was sponsored by the National Natural Science Foundation of China (Nos. 51708564, 51808193, and 51678578), Guangdong Basic and Applied Basic Research Foundation (No. 2020A1515011271), and Shenzhen Natural Science Foundation (JCYJ20190807162401662). The authors are grateful to these institutions for their support.

\section{References}

[1] K. R. Hong, "Typical underwater tunnels in the mainland of China and related tunneling technologies," Engineering, vol. 6, no. 3, pp. 871-879, 2017.

[2] Z. Wang, W. Yao, Y. Cai, B. Xu, Y. Fu, and G. Wei, “Analysis of ground surface settlement induced by the construction of a large-diameter shallow-buried twin-tunnel in soft ground,"
Tunnelling and Underground Space Technology, vol. 83, pp. 520-532, 2019.

[3] Y. Fang, Z. Chen, L. Tao, J. Cui, and Q. Yan, "Model tests on longitudinal surface settlement caused by shield tunnelling in sandy soil," Sustainable Cities and Society, vol. 47, Article ID 101504, 2019.

[4] J. Zhang, F. Yang, J. Yang, X. Zheng, and F. Zeng, "Upperbound stability analysis of dual unlined elliptical tunnels in cohesive-frictional soils," Computers and Geotechnics, vol. 80, pp. 283-289, 2016.

[5] J. Zhang, L. Ding, Y. Liang, J. Y. Zong, and Z. Y. Li, "Upperbound finite element adaptive analysis of plane strain heading in soil with a soft upper layer and hard lower layer," Advances in Civil Engineering, vol. 2019, Article ID 7387635, 10 pages, 2019.

[6] C.-G. Lin, Z.-M. Zhang, S.-M. Wu, and F. Yu, "Key techniques and important issues for slurry shield under-passing embankments: a case study of Hangzhou Qiantang river tunnel," Tunnelling and Underground Space Technology, vol. 38, pp. 306-325, 2013.

[7] Y. N. Ren, H. Q. Wang, and J. H. Wang, "Settlement control of Qiantang river embankments during undercrossing of EPB shield tunnels," Chinese Journal of Geotechnical Engineering, vol. 35, no. 2, pp. 936-939, 2013.

[8] Z. M. Zhang, C. G. Lin, S. M. Wu, G.-S. Liu, C.-S. Wang, and W.-B. Xie, "Analysis and control of ground settlement of embankments in construction of cross-river shield tunnels," Chinese Journal of Geotechnical Engineering, vol. 33, no. 6, pp. 977-984, 2011.

[9] Z. Y. Jiang and J. Yu, "The analysis of stratum settlement for a large diameter slurry shield obliquely under-passing embankment of the Yangtze river," Advanced Materials Research, vol. 919-921, pp. 895-901, 2014.

[10] C. Q. Yao, X. G. Wu, and Y. Q. Chen, "Protection scheme of shield tunneling through Yangtze river levee for Wuhan rail Transit," Construction Technology, vol. 47, no. 24, 2018.

[11] Y. Z. Zhang, P. J. Xia, W. Zhu, and F. Min, "Analysis of stratum deformation and stability: a case study of the Nanjing Weisan road river-crossing tunnel passing under the Yangtze river embankment," Modern Tunnelling Technology, vol. 52, no. 4, pp. 151-157, 2015.

[12] C. Ji and L. Wang, "On deformation control for the shield passing through old embankment to be rebuilt in soft soil area," Modern Tunnelling Technology, vol. 56, no. 3, pp. 108-117, 2019.

[13] W. B. Xie and W. Y. Wu, "Test and analysis on ground subsidence due to the large-diameter slurry shield underpassing the Qiantang River embankment," Modern Tunnelling Technology, vol. 48, no. 4, pp. 142-147, 2011.

[14] D. S. Chu, Study of EPB Shield Tunnelling Parameters of Changsha Metro Passing beneath Xiangjiang River. Master Dissertation, Central South University, Changsha, China, 2012.

[15] S. H. Prassetyo and M. Gutierrez, "Influence of embankment loading on the hydro-mechanical response of a NATM tunnel in saturated ground," in Proceedings of the 50th U.S. Rock Mechanics/Geomechanics Symposium, Houston, Texas, June 2016.

[16] X. N. Gong, Advanced Soil Mechanics, Zhejiang University Press, Hangzhou, China, 1996.

[17] W. B. Zhou, Shield Tunnelling Technology and its Application, China Architecture and Building Press, Beijing, China, 2004. 
[18] L. C. Yin, Z. H. Zhu, and Y. Z. Li, Japanese New Technology in Tunnel Shielding, Huazhong University of Science and Technology, Wuhan, China, 1999.

[19] V. Guglielmetti, P. Grasso, and A. Mahtab, Mechanized Tunneling in Urban Areas: Design Methodology and Construction Control, Taylor and Francis Group, London, UK, 2008.

[20] Y. Shan, S. Zhou, and Y. Shu, "Differential settlement and soil dynamic stress of a culvert-embankment transition zone due to an adjacent shield tunnel construction," KSCE Journal of Civil Engineering, vol. 22, no. 7, pp. 2325-2333, 2018.

[21] Y. Liang, X. Chen, J. Yang, J. Zhang, and L. Huang, "Analysis of ground collapse caused by shield tunnelling and the evaluation of the reinforcement effect on a sand stratum," Engineering Failure Analysis, vol. 115, Article ID 104616, 2020.

[22] Y. Liang, Y.-F. Xiao, and Y.-X. Lin, "Pore water pressure responses in sand stratum during shield tunnelling: a case study," Advances in Civil Engineering, vol. 2020, Article ID 6139246, 9 pages, 2020. 